\title{
ANALISIS TINGKAT KEPUASAN KONSUMEN TERHADAP PELAYANAN WARUNK BENDITO DI KAWASAN MEGAMAS MANADO
}

\author{
Mulyadi Buton \\ Rine Kaunang \\ Sherly Gladys Jocom
}

Naskah diterima melalui Website Jurnal Ilmiah agrisosioekonomi@unsrat.ac.id

: Senin, 22 April 2019

Disetujui diterbitkan

: Jumat, 26 April 2019

\begin{abstract}
This study aims to determine the level of customer satisfaction with Warunk Bendito service in the Megamas Manado area. This research was conducted in three months starting from preparation to compiling the research report from January 2019 to March 2019. This study uses primary and secondary data. The sampling method in this study was done by accidental sampling. Primary data collection is done by interview technique directly to 60 respondents based on questionnaires that have been prepared in advance. While secondary data collection is obtained from existing documents Warunk Bendito, books available at local bookstores and the internet through google scholar searches to access articles from various scientific journals and other university "skripsi" related to this research, especially concerning consumer satisfaction with service. The results of the study using the Likert Scale analysis showed that the index of the level of consumer satisfaction with the service of Warunk Bendito in the Megamas area of Manado was at the point of 83.2\% which was in the very satisfied category. ${ }^{*}$ jnkd+erprm*
\end{abstract}

Keywords: analysis, satisfaction level, consumer, service, likert scale

\begin{abstract}
ABSTRAK
Penelitian ini bertujuan untuk untuk mengetahui tingkat kepuasan konsumen terhadap pelayanan Warunk Bendito di Kawasan Megamas Manado. Penelitian ini di Warunk Bendito Kawasan Megamas Kota Manado dalam waktu tiga bulan mulai dari persiapan hingga penyusunan laporan hasil penelitian yaitu dari bulan Januari 2019 sampai Maret 2019. Penelitian ini menggunakan data primer dan sekunder. Metode pengambilan sampel dalam penelitian ini dilakukan dengan sampel kebetulan (accidental sampling). Pengumpulan data primer dilakukan dengan teknik wawancara secara langsung kepada 60 responden berdasarkan kuesioner yang telah dipersiapkan sebelumnya. Sedangkan pengumpulan data sekunder diperoleh dari dokumen yang ada Warunk Bendito, buku-buku yang tersedia di toko buku lokal dan internet seperti pencarian google scholar untuk mengakses artikel dari berbagai jurnal ilmiah dan skripsi dari perguruan tinggi lain yang berkaitan dengan penelitian ini terutama menyangkut kepuasan konsumen terhadap pelayanan. Hasil penelitian dengan menggunakan analisis Skala Likert menunjukan bahwa indeks tingkat kepuasan konsumen terhadap pelayanan Warunk Bendito di kawasan megamas Manado berada pada titik $83,2 \%$ yang masuk kategori sangat puas. ${ }^{*}$ inkd+erprm*
\end{abstract}

Kata kunci: analisis, tingkat kepuasan, konsumen, pelayanan, skala likert

Agrisosioekonomi: 


\section{PENDAHULUAN}

\section{Latar Belakang}

Dalam era globalisasi ini persaingan bisnis menjadi sangat tajam baik di pasar domestik maupun pasar internasional atau global. Salah satu cara memenangkan persaingan adalah perusahaan harus mampu memberikan kepuasan kepada para pelanggannya, misalnya dengan memberikan produk yang mutunya lebih baik, harganya lebih murah, penyerahan produk yang lebih cepat dan pelayanan yang lebih baik dari pada pesaingnya sehingga menyebabkan pelanggan menjadi lebih puas (Nugroho dan Puriarta, 2011).

Dalam pengembangan suatu usaha dibutuhkan pemasaran. Pemasaran merupakan salah satu unsur dalam kegiatan usaha, terutama menu siap saji, kebijakan yang diambil dalam pemasaran mempengaruhi maju mundurnya usaha tersebut. Dalam suatu usaha yang dihadapi saat ini bukan hanya bagaimana pelayanan saja, tetapi yang paling penting adalah beberapa cara pemasaran yang dapat digunakan untuk mempengaruhi pembeli. Menurut Kothler (2000), yang mempunyai peranan yang sangat penting harga (price), tempat (place) dan promosi (promotion).

Meningkatkan dan mempertahankan usaha serta persaingan yang ketat diperlukan suatu cara, salah satunya yaitu dengan meningkatkan kepuasan konsumen terhadap pelayanan. Konsumen harus dipuaskan, jika tidak berdampak buruk bagi usaha itu sendiri, seperti menurunnya pendapatan dan hilangnya pelanggan, maka pemilik usaha harus berusaha untuk memaksimalakan pelayanan terhadap pelanggan.

Semakin terpenuhi harapan-harapan dari konsumen terhadap pelayanan tentu konsumen semakin puas. Konsumen merasa puas, maka ia melakukan pembelian secara berulang-ulang. Untuk memberikan kepuasan konsumen terhadap pelayanan perusahaan harus dapat melayani konsumen dengan baik. Perusahaan juga melakukan strategi strategi untuk membentuk kepuasan konsumen dengan memberikan pelayanan yang berkualitas. Dengan kualitas yang baik mendorong konsumen untuk menjalin hubungan baik dengan perusahaan. Dengan demikian perusahaan dapat meningkatkan kepuasan konsumen dengan meminimalkan pengalaman yang tidak mengenakan dari konsumen. Kepuasan konsumen dapat menciptakan kesetiaan dan loyalitas konsumen kepada perusahaan yang memberikan kualitas memuaskan (Tjiptono, 2002).

Kotler (2000), menyebutkan kepuasan konsumen adalah perasaan senang atau kecewa seseorang yang berasal dari perbandingan antara kesannya terhadap kinerja (hasil) sesuatu produk dengan harapannya. Kepuasan adalah semacam langkah perbandingan antara pengalaman dengan hasil evaluasi, dapat menghasilkan sesuatu yang nyaman secara rohani, bukan hanya nyaman karena dibayangkan atau diharapkan. Puas atau tidak puas bukan merupakan emosi melainkan sesuatu hasil evaluasi dari emosi.

Perkembangan pesat di Manado mendorong munculnya usaha-usaha baru kreatif dan inovatif. Perekonomian membawa dampak bagi kehidupan manusia terutama dunia usaha pada saat ini maka hadirlah Warunk Bendito di Kota Manado. Warunk Bendito didirikan pada tahun 2016 dan menjadi tempat nongkrong anak muda serta tempat makan bersama relasi-relasi bisnis atau dengan keluarga. Warunk Bendito menyediakan berbagai jenis makanan dan minuman dengan memberikan pelayanan yang maksimal bagi pengujung serta adanya sarana live music dan wifi gratis yang jarang dimiliki oleh kafe lainnya. Di samping itu banyaknya usaha yang bermunculan dan berdekatan dengan Warung Bendito sehingga berdampak pada persaingan yang ketat baik sejenis maupun tidak sejenis. Pemasaran merupakan salah satu kegiatan yang dilakukan dalam menghadapi persaingan, pengembangan usaha dan untuk mendapatkan laba. Warunk Bendito menggunakan strategi yang berbeda dengan kafe-kafe lainnya.

Perkembangan perekonomian membawa dampak bagi kehidupan manusia terutama dunia usaha pada saat ini. Masalah-masalah akan selalu muncul baik dari dalam maupun dari luar. Masalah yang di hadapi saat ini di lihat dari luar pada Warunk Bandito adalah tidak 
mempunyai lahan parkir yang memadai dan lokasi Warunk Bendito terletak berdekatan dengan rumah makan dan kafe lainnya sehingga bisa mempengaruhi jumlah pengunjung yang datang. Sedangkan di lihat dari dalam masalah pada Warunk Bendito adalah ketika banyak pengunjung yang datang terkadang sulit untuk mendapatkan tempat duduk dan karyawan merasa kesulitan saat melayani pengunjung yang begitu banyak yang datang di Warunk Bendito.

\section{Perumusan Masalah}

Berdasarkan uraian latar belakang di atas, maka dapat dirumuskan masalah dalam penelitian ini adalah bagaimana tingkat kepuasan konsumen terhadap pelayanan Warunk Bendito di Kawasan Megamas Manado.

\section{Tujuan Penelitian}

Penelitian ini bertujuan untuk mengetahui tingkat kepuasan konsumen terhadap pelayanan Warunk Bendito di Kawasan Megamas Manado.

\section{Manfaat Penelitian}

Berdasarkan uraian pada rumusan masalah maka penelitian ini diharapkan dapat memberikan pengetahuan sebagai sumbangan informasi bagi pihak yang berkepentingan khususnya Warunk Bendito dalam usaha pencapaian kepuasan konsumen terhadap pelayanan.

\section{METODE PENELITIAN}

\section{Tempat dan Waktu Penelitian}

Penelitian ini dilakukan di Warunk Bendito Kawasan Megamas Kota Manado dalam waktu tiga bulan mulai dari persiapan hingga penyusunan laporan hasil penelitian yaitu dari bulan Januari 2019 sampai Maret Oktober 2019.

\section{Metode Pengumpulan Data}

Sumber data yang digunakan dalam penelitian ini adalah data primer dan sekunder. Data primer yang digunakan dalam penelitian ini adalah responden. Adapun individu atau perorangan yang dijadikan responden dalam penelitian ini adalah konsumen yang datang ke
Warung Bendito Kawasan Megamas Kota Manado. Sumber data sekunder adalah data tertulis seperti buku, arsip, dokumen, dan kepustakaan yang berkaitan dengan masalah yang diteliti.

\section{Metode Pengambilan Sampel}

Populasi dari penelitian ini adalah para konsumen yang datang ke Warunk Bendito Kawasan Megamas Kota Manado. Metode pengambilan sampel dalam penelitian ini dilakukan dengan Accidental Sampling yaitu dengan mengambil sampel secara kebetulan bertemu dengan peneliti. Jumlah sampel yang diambil dalam penelitian ini adalah 60 orang dengan 10 pertanyaan.

\section{Pengukuran Variabel}

Variabel yang diukur dalam penelitian ini sebagai berikut :

1. Karakterisrik Responden

a. Jenis kelamin, yaitu perbedaan antara laki-laki dengan perempuan yang menjadi pelanggan atau responden di Warunk Bendito.

b. Usia, yaitu umur seseorang yang menjadi pelanggan atau responden di Warung Bendito.

c. Pekerjaan, yaitu adalah sesuatu yang dikerjakan untuk mendapatkan nafkah atau pencaharian yang menjadi pelanggan atau responden di Warunk Bendito.

d. Pendidikan, yaitu suatu usaha mengembangkan suatu kepribadian dan kemampuan di dalam dan diluar sekolah dan berlangsung seumur hidup yang menjadi pelanggan atau responden di Warunk Bendito.

e. Pendapatan, yaitu adalah semua penghasilan yang didapat oleh keluarga baik berupa uang ataupun jasa yang menjadi pelanggan atau respoden di Warunk Bendito

2. Variabel Tingkat Kepuasan Konsumen Terhadap Pelayanan

a. Reliability, yaitu kemampuan untuk melaksanakan jasa yang di janjikan dengan tepat dan terpercanya.

b. Responsive, yaitu respon atau kesiapan karyawan dalam membantu pelanggan 
dan memberikan pelayanan dengan cepat dan tanggap.

c. Assurance, yaitu meliputi kemampuan karyawan atas pengetahuan terhadap prouk secara tepat, kualitas kerahtamahan, perahtian dan kesopanan dalam memberikan pelayanan.

d. Emphaty, yaitu perhatian secara individual yang diberikan perusahaan kepada pelanggan, seperti kemudahan untuk menghubungi perusahaan, kempampuan karyawan untuk berkomunikasi dengan pelanggan.

e. Tangible, yaitu meliputi penampialn fasilitas fisik, seperti gedung ruangan, tersedia tempat parkir, kebrsihan, kerapihan dan kenyamanan ruangan.

\section{Metode Analisis Data}

Penelitian ini menggunakan teknik analisis deskriptif. Analisis deskriptif digunakan untuk data yang bersifat kualitatif dan disajikan dalam bentuk tabulasi. Hasil yang diperoleh kemudian dipersentasekan berdasarkan jumlah responden.

Analisis data dilakukan dengan cara membuat tabulasi distribusi responden dari setiap variabel yang diteliti untuk mengetahui kepuasan konsumen terhadap pelayanan dilihat dari jenis kelamin, usia, pekerjaan, pendidikan terakhir, mengetahui keberadaan warung bandito dan pendapatan pada tingkat kepuasan konsumen terhadap Pelayanan Warunk Bandito di Kawasan Megamas Manado yang diukur berdasarkan skala likert.

Dalam penelitian ini di susun 10 pernyataan dengan total responden 60 orang. Jawaban setiap instrument yang menggunakan skala likert, yang berupa kata-kata, antara lain :

$$
\begin{array}{ll}
\mathrm{SP} & =\text { Sangat Puas } \\
\mathrm{P} & =\text { Puas } \\
\mathrm{CP} & =\text { Cukup Puas } \\
\mathrm{KP} & =\text { Kurang Puas } \\
\mathrm{TP} & =\text { Tidak Puas }
\end{array}
$$

Bila :

SP diberi skor $=5$

$\mathrm{P}$ diberi skor $=4$

$\mathrm{CP}$ diberi skor $=3$

$\mathrm{KP}$ diberi skor $=2$

$\mathrm{TP}$ diberi skor $=1$
Dengan cara perhitungan skor masingmasing pernyataan:

Jumlah skor tiap kriteria = capaian skor $\mathrm{X}$ jumlah responden.

$$
\begin{aligned}
& \mathrm{SP} 5=5 \times 60=300 \\
& \mathrm{P} 4=4 \times 60=240 \\
& \mathrm{CP} 3=3 \times 60=180 \\
& \mathrm{KP} 2=2 \times 60=120 \\
& \mathrm{TP} 1=1 \times 60=60
\end{aligned}
$$

Jumlah skor ideal untuk setiap pernyataan skor tertinggi $=300$ (sangat puas)

Jumlah skor terendah $=60$ (tidak puas)

Dengan interpretasi nilai :

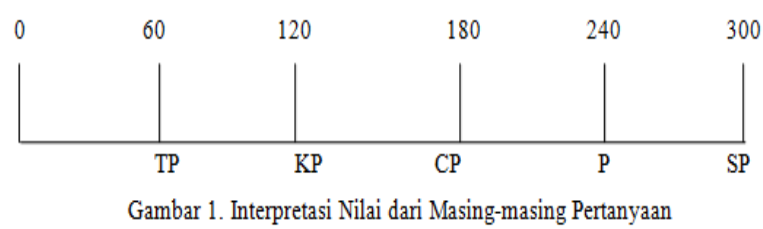

Cara perhitungan skor keseluruhan untuk mengetahui tingkat kepuasan konsumen:

Jumlah skor seluruh kriterium = capaian jumlah skor $\mathrm{X}$ jumlah responden $\mathrm{X}$ instrumen pertanyaan

Untuk :

$$
\begin{aligned}
& \mathrm{SP} 5=5 \times 60 \times 10=3000 \\
& \mathrm{P} 4=4 \times 60 \times 10=2400 \\
& \mathrm{CP} 3=3 \times 60 \times 10=1800 \\
& \mathrm{KP} 2=2 \times 60 \times 10=1200 \\
& \mathrm{TP} 1=1 \times 60 \times 10=600
\end{aligned}
$$

Jumlah skor ideal untuk keseluruhan pernyataan $=3000$ (sangat puas)

Jumlah skor rendah $=600$ (tidak puas)

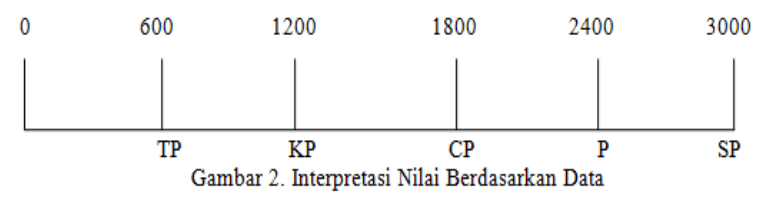

Analisis data yang digunakan merupakan analisis deskriptif yang yang di analisis dengan menggunakan skala pengukuran Likert Scale. Adalah sebagai berikut :

Kepuasan Konsumen $=\frac{\text { Jumlah Skor Hasil Pengumpulan Data }}{\text { Jumlah Skor Ideal (Tertinggi) }} \times 100 \%$

Dengan interpretasi nilai :

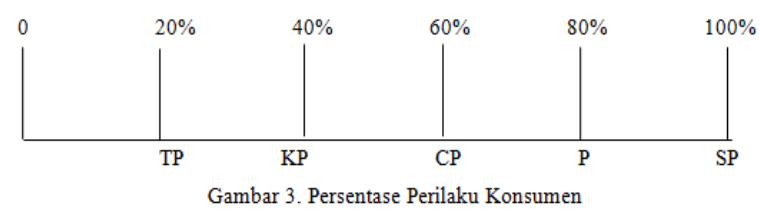


Keterangan kriteria interpretasi skor keputusan konsumen :

$$
\begin{array}{ll}
\text { Angka 0\% - 20\% } & =\text { Tidak Puas } \\
\text { Angka 21\%-40\% } & =\text { Kurang Puas } \\
\text { Angka 41\%-60\% } & =\text { Cukup Puas } \\
\text { Angka 61\%-80\% } & =\text { Puas } \\
\text { Angka } 81 \%-100 \% & =\text { Sangat Puas }
\end{array}
$$

\section{HASIL DAN PEMBAHASAN}

\section{Deskripsi Usaha Warunk Bendito}

Penelitian ini dilakukan pada konsumen Warunk Bendito yang berlokasi Dikawasan Megamas Manado, penelitian bertujuan untuk menganalisis kepuasan responden Warunk Bendito, yaitu untuk mengetahui tingkat kepuasan responden terhadap pelayanan. Pelaksanaan penelitian dilakukan dengan cara memerikan sejumlah pertanyaan tertulis (kuesioner) kepada 60 respoden sebagai sampel. Teknik pengambilan sampel dengan menggunakan metode Accidental Sampling.

Bendito berasal dari bahasa Yunani, yang berarti Miracle/Keajaiban. Untuk pemilihan kata warunk itu agar konsep usaha ini tidak hanya terpaku pada satu menu melainkan banyak menu. Warunk Bendito didirikan pada tahun 2016 oleh Bapak Reza Irawan yang berlokasi Dikawasan Megamas Manado dan sudah membuka cabang di Jalan Sam Ratulangi 45 Teras Dolphin Donuts.

Produk makanan di Warunk Bendito dijamin enak dan halal semua tersedia di Warunk Bendito. Untuk kategori snack, Warunk Bendito menyediakan pisang goroho, pisang goreng, french fries, ubi goreng bumbu, banana sushi, roti panggang (Ropang), pisang bakar atau king banana grill. Tidak hanya itu. Warunk Bendito juga menyediakan berbagai macam makanan seperti nasi bistik hot plate, nasi tuna bakar, nasi tuna , nasi goreng roa, nasi goreng ikan asin, nasi goreng cakalang, nasi gila, nasi goreng gila, tinutuan, nasi soto ayam, dan nasi ayam geprek.

Warunk Bendito juga menyediakan berbagai macam indomie, mulai dari indomie ceplok hingga indomie chicken katsu, indomie salt and pepper, indomie sambal, dan berbagai macam indomie lainnya. Tidak berhenti di situ saja. Warunk Bendito juga menyediakan berbagai minuman seperti milo jurassic, iced cappuccino, red velvet latte, green tea latte, d'Gorillaz (banana smoothie), al pucino (jus alpukat cappuccino), blue lagoon, P.P.A.P, milkshake, iced chocolate, dan berbagai minuman lainnya.

Lokasi usaha Warunk Bendito Dikawasan Megamas Manado ini dapat dikatakan strategis karena berada dekat dengan jalan raya dan dapat dilalui alat transportasi dengan mudah. Oleh karena itu, dengan lokasi strategis sehingga dapat menjangkau para konsumen datang ke Warunk Bendito serta dapat mendukung kelancaran usaha.

Untuk Warunk Bendito Sendiri memeliki 2 shift untuk para karyawannya, yaitu shift pagi sampai siang dan sore sampai malam dengan masing-masing shif ada 8-10 karyawan, dan untuk pendapatan usaha Warunk Bendito Dikawasan Megamas Manado 150 juta perbulan sehingga gaji yang diterima karyawan 1,7 juta perbulan.

\section{Karakteristik Responden}

\section{Jenis Kelamin}

Berdasarkan hasil penelitian dapat diketahui bahwa dari 60 responden yang diambil sebagai sampel, responden pria sebanyak 34 orang $(56,7 \%)$ dan jumlah responden wanita yaitu sebanyak 24 orang $(43,3 \%)$. Sehingga dapat disimpulkan bahwa mayoritas responden pria dalam penelitian ini lebih banyak yaitu 34 orang atau sebanyak $43,3 \%$ dari jumlah seluruh sampel.

\section{Usia}

Berdasarkan hasil penelitian, dapat diketahui bahwa mayoritas responden yang paling banyak dalam penelitian ini berusia 1525 tahun yaitu sebanyak 21 orang atau $35 \%$ dari jumlah seluruh sampel, sedang untuk urutan selanjutnya yaitu usia 26-30 tahun sebanyak 18 orang (30\%) dan usia 31-35 tahun sebanyak 9 orang (15\%) dan usia 36-40 tahun sebanyak 7 orang $(11,7 \%)$ serta usia $41-50$ sebanyak 5 orang $(8,3 \%)$. 


\section{Pekerjaan}

Berdasarkan hasil penelitian, dapat diketahui bahwa dari 60 orang responden yang dijadikan sampel dalam penelitian ini yang paling banyak adalah pelajar/mahasiswa yaitu sebanyak 37 orang $(61,7 \%)$ sedang untuk jenis pekerjaan lain dalam penelitian ini yaitu sebagai karyawan (swasta/negeri) sebanyak 13 orang $(21,7 \%)$, ibu rumah tangga sebanyak 6 orang (10\%) serta 4 orang $(6,7 \%)$ bekerja sebagai wirausaha.

\section{Pendidikan}

Berdasarkan hasil penelitian, tingkat pendidikan yang dimiliki responden berdasarkan pendidikan yang paling banyak adalah Akademi/Universitas yaitu sebanyak 39 orang $(65 \%)$ diikuti dengan pendidikan SMA/SMK sebanyak 10 orang $(16,7 \%)$ dan S1/S2 sebanyak 7 orang $(11,7 \%)$ serta SD/SMP sebanyak 4 orang $(6,7 \%)$.

\section{Pendapatan}

Berdasarkan hasil penelitian, tingkat pendidikan yang dimiliki responden berdasarkan tingkat pendapatan yang paling banyak adalah $\leq 500.000$ yaitu sebanyak 22 orang $(36,7 \%)$ dan diikuti responden yang berpenghasilan $\leq 1.000 .000$ sebanyak $15(25 \%)$ dan $\leq 2.000 .000$ sebanyak 11 orang $(18,3 \%)$, $\leq 3.000 .000$ sebanyak 8 orang $(13,3 \%)$ serta $\leq 4.000 .000$ sebanyak 4 orang $(6,7 \%)$.

\section{Penilaian Tingkat Kepuasan Konsumen}

\section{Reliability (Keandalan)}

Reliability yaitu, kemampuan untuk melaksanakan jasa yang dijanjikan dengan tepat dan terpercanya. Penelitian ini menggunakan 2 item pertanyaan Reliability untuk mengukur kepuasan konsumen terhadap pelayanan dilihat dari dimensi keandalan.

Tabel 1. Tingkat Kepuasan Konsumen Mengenai Kecepatan Makanan Yang Dipesan Lilihat dari Dimensi Reliability (Keandala)

\begin{tabular}{lcccc}
\hline Jawaban & Skor & $\begin{array}{c}\text { Jumlah } \\
\text { Responden }\end{array}$ & $\begin{array}{c}\text { Persentase } \\
(\%)\end{array}$ & $\begin{array}{c}\text { Total } \\
\text { Skor }\end{array}$ \\
\hline Sangat Puas & 5 & 12 & $20 \%$ & 60 \\
Puas & 4 & 36 & $60 \%$ & 144 \\
Cukup Puas & 3 & 12 & $20 \%$ & 36 \\
Kurang Puas & 2 & - & - & - \\
Tidak Puas & 1 & - & - & - \\
\hline & Jumlah & 60 & $100 \%$ & 240 \\
\hline
\end{tabular}

Sumber: Diolah Dari Data Primer, 2019
Berdasarkan pada Tabel 1, dapat diketahui bahwa responden yang menganggap puas mengenai kecepatan makanan yang dipesan sebanyak 36 orang (60\%) dan 12 orang (20\%) menganggap sangat puas dan cukup puas. Dengan total skor kecepatan makanan yang dipesan adalah 240 dan interpretasi sebesar $80 \%$. Dan termasuk kategori sangat puas.

\section{Responsive (Tanggapan)}

Responsive yaitu, respon atau kesiapan karyawan dalam membantu pelanggan dan memberikan pelayanan dengan cepat dan tanggap, yang meliputi kesiapan karyawan dalam melayani pelanggan, kecepatan karyawan dalam melayani transaksi dan penanganan keluhan pelanggan. Penelitian ini menggunakan 2 item pertanyaan Responsive untuk mengukur tingkat kepuasan konsumen terhadap pelayanan dilihat dari dimensi Responsive (Tanggapan).

Tabel 2. Tingkat Kepuasan Konsumen Mengenai Kecepatan Pelayanan Dalam Melayani Dilihat dari Dimensi Responsive (Tanggapan)

\begin{tabular}{|c|c|c|c|c|}
\hline Jawaban & Skor & $\begin{array}{c}\text { Jumlah } \\
\text { Responden }\end{array}$ & $\begin{array}{c}\text { Persentase } \\
(\%)\end{array}$ & $\begin{array}{l}\text { Total } \\
\text { Skor }\end{array}$ \\
\hline Sangat Puas & 5 & 22 & $36,7 \%$ & 110 \\
\hline Puas & 4 & 30 & $50 \%$ & 120 \\
\hline Cukup Puas & 3 & 8 & $13,3 \%$ & 24 \\
\hline Kurang Puas & 2 & - & - & - \\
\hline Tidak Puas & 1 & - & - & - \\
\hline & Jumlah & 60 & $100 \%$ & 254 \\
\hline
\end{tabular}

Sumber: Diolah Dari Data Primer, 2019

Berdasarkan pada Tabel 2 dapat diketahui bahwa jumlah responden yang paling banyak adalah yang menggangap puas mengenai kecepatan pelayanan dalan melayani yaitu sebanyak 30 orang $(50 \%)$ dan sangat puas sebanyak 22 orang $(36,7 \%)$ serta yang menganggap cukup puas sebanyak 8 orang $(13,3 \%)$. Dengan tota skor yang diperoleh 254 dan interpretasi sebanyak $84,7 \%$. Dan termasuk kategori sangat puas.

Tabel 3. Tingkat Kepuasan Konsumen Mengenai Sikap Ramah Karyawan Terhadap Konsumen Dilihat dari Dimensi Responsive (Tanggapan)

\begin{tabular}{lcccc}
\hline Jawaban & Skor & $\begin{array}{c}\text { Jumlah } \\
\text { Responden }\end{array}$ & $\begin{array}{c}\text { Persentase } \\
(\%)\end{array}$ & $\begin{array}{c}\text { Total } \\
\text { Skor }\end{array}$ \\
\hline Sangat Puas & 5 & 21 & $35 \%$ & 105 \\
Puas & 4 & 38 & $63,3 \%$ & 152 \\
Cukup Puas & 3 & 1 & $1,7 \%$ & 3 \\
Kurang Puas & 2 & - & - & - \\
Tidak Puas & 1 & - & - & - \\
\hline & Jumlah & 60 & $100 \%$ & 260 \\
\hline
\end{tabular}

Sumber: Diolah Dari Data Primer, 2019 
Berdasarkan pada Tabel 3, dapat diketahu bahwa jumlah responden yang paling banyak menjawab mengenai sikap ramah karyawan terhadap konsumen adalah puas sebanyak 38 orang $(63,3 \%)$ dan menjawab sangat puas sebanyak 21 orang $(35 \%)$ serta yang menjawab cukup puas sebanyak 1 orang $(1,7 \%)$. Dengan total skor yang diperoleh 260 dan interpretasi sebanyak $86,7 \%$. Dan termasuk kategori sangat puas.

\begin{tabular}{l} 
Tabel 4. Rekapitulasi Total Skor, Tingkat Kepuasan Konsumen dan Interpretasi Terhadap Pelayanan \\
\multicolumn{4}{c}{ Dilihat dari Dimensi Responsive (Tanggapa) } \\
\begin{tabular}{llccc} 
& & & \\
\hline 1 & Pertanyaan & Total Skor & Kepuasan Konsumen $(\%)$ & Interpretasi \\
\hline 2 & Kecepatan pelayanan dalam melyani & 254 & 84,7 & Sangat Puas \\
& Sikap ramah Karyawan terhadap konsumen & 260 & $86,7 \%$ & Sangat Puas \\
\hline Total & 514 & $85,7 \%$ & Sangat Puas \\
\hline Sumber: Diolah Dari Data Primer 2019 & & &
\end{tabular}
\end{tabular}

Tabel 4 menunjukan bahwa dari seluruh indikator tingkat kepuasan konsumen terhadap pelayanan terletak pada skor 514 dan persentase tingkat kepuasan sebesar $85,7 \%$. Artinya konsumen sangat puas terhadap pelayanan yang diberikan Warunk Bendito dilihat dari dimensi Responsive dan indikator yang memperoleh persentasi kepuasan konsumen yang tinggi adalah sikap ramah karyawan terhadap konsumen yaitu sebesar $86,7 \%$. Hal ini menunjukan bahwa responden sangat puas terhadap sikap ramah karyawan terhadap konsumen.

\section{Tangible (Fasilitas)}

Tangible yaitu, meliputi penampilan fasilitas fisik, seperti ruangan, tersedianya tempat parkir, kebersihan, kerapihan dan kenyamanan ruangan. Penelitian ini menggunakan 3 item pertanyaan Tangible untuk mengukur tingkat kepuasan konsumen terhadap pelayanan dilihat dari dimensi Tangible (Fasilitas).

Tabel 5. Tingkat Kepuasan Konsumen Mengenai Kebersihan Dalam Ruangan Dilihat dari Dimensi Tangible (Fasilitas)

\begin{tabular}{lcccc}
\hline Jawaban & Skor & $\begin{array}{c}\text { Jumlah } \\
\text { Responden }\end{array}$ & $\begin{array}{c}\text { Persetase } \\
(\%)\end{array}$ & $\begin{array}{c}\text { Total } \\
\text { Skor }\end{array}$ \\
\hline Sangat Puas & 5 & 21 & $35 \%$ & 105 \\
Puas & 4 & 35 & $58,3 \%$ & 140 \\
Cukup Puas & 3 & 4 & $6,7 \%$ & 12 \\
Kurang Puas & 2 & - & - & -- \\
Tidak Puas & 1 & - & - & - \\
\hline & Jumlah & 60 & $100 \%$ & 257
\end{tabular}

Sumber: Diolah Dari Data Primer 2019
Berdasarkan pada Tabel 5, dapat diketahui bahwa jumlah responden yang paling banyak menjawab mengenai kebersihan dala ruangan adalah menjawab puas yaitu sebanyak 35 orang $(58,3 \%)$ dan yang menjawab sangat puas sebanyak 21 orang $(35 \%)$ serta yang menjawab cukup puas sebanyak 4 orang $(6,7)$. Dengan total skor yang diperoleh 257 dan interpretasi sebanyak 85,7\%. Dan termasuk kategori sangat puas.

\begin{tabular}{lcccc} 
Tabel 6. & $\begin{array}{c}\text { Tingkat } \\
\text { Tersedianya } \\
\text { Dimensi Tangible (Fasillitas) }\end{array}$ & $\begin{array}{c}\text { Kepuasan } \\
\text { Tempat }\end{array}$ & $\begin{array}{c}\text { Konsumen } \\
\text { Parkir }\end{array}$ & $\begin{array}{c}\text { Mengenai } \\
\text { Dilihat }\end{array}$ \\
& Skor & $\begin{array}{c}\text { Jumlah } \\
\text { Responden }\end{array}$ & $\begin{array}{c}\text { Persentase } \\
(\%)\end{array}$ & $\begin{array}{c}\text { Total } \\
\text { Skor }\end{array}$ \\
\hline Jawaban & & 13 & $21.7 \%$ & 65 \\
& 5 & 37 & $61,7 \%$ & 148 \\
\hline Sangat Puas & 4 & 10 & $16,6 \%$ & 30 \\
Puas & 3 & - & - & - \\
Cukup Puas & 2 & - & - & - \\
Kurang Puas & 1 & 60 & $100 \%$ & 243 \\
Tidak Puas & 1 & Jumlah &
\end{tabular}

Sumber : Diolah Dari Data primer 2019

Berdasarkan pada Tabe 6, dapat diketahui bahwa jumlah responden yang paling banyak menjawab mengenai tersedianya tempat parkir adalah yang menjawab puas yaitu sebanyak 37 orang $(61,7 \%)$ dan yang menjawab sangat puas sebanyak 13 orang $(21,7 \%)$ serta yang menjawab cukup puas 10 orang $(16,6 \%)$. Dengan total skor yang diperoleh 243 dan interpretasi sebanyak 81\%. Dan termasuk kategori sangat puas.

Tabel 7. Tingkat Kepuasan Konsumen Mengenai Kerapihan dan Kenyamanan Ruangan Dilihat dari Dimensi Tangible (Fasilitas)

\begin{tabular}{lcccc}
\hline Jawaban & Skor & $\begin{array}{c}\text { Jumlah } \\
\text { Responden }\end{array}$ & $\begin{array}{c}\text { Persentase } \\
(\%)\end{array}$ & $\begin{array}{c}\text { Total } \\
\text { Skor }\end{array}$ \\
\hline Sangat Puas & 5 & 16 & $26,7 \%$ & 80 \\
Puas & 4 & 32 & $53,3 \%$ & 128 \\
Cukup Puas & 3 & 12 & $20 \%$ & 36 \\
Kurang Puas & 2 & - & - & - \\
Tidak Puas & 1 & - & - & - \\
\hline \multicolumn{5}{r}{} \\
\hline
\end{tabular}

Sumber: Diolah Dari Data Primer, 2019

Berdasarkan pada Tabel 7, dapat diketahui bahwa jumlah responden yang paling banyak menjawab mengenai kerapihan dan kenyamanan ruangan adalah puas yaitu sebanyak 32 orang $(53,3 \%)$ dan yang menjawab sangat puas sebanyak 16 orang $(26,7 \%)$ serta yang menjawab cukup puas 12 orang (20\%). Dengan total skor yang diperoleh 244 dan interpretasi sebanyak 81,3\%. Dan termasuk kategori puas. 
Tabel 8. Tingkat Kepuasan Konsumen Mengenai Fasilitas Pendukung Cukup menunjang (tv, musik, wifi) Dilihat dari Dimensi Reliability (Keandalan)

\begin{tabular}{lcccc}
\hline Jawaban & Skor & $\begin{array}{c}\text { Jumlah } \\
\text { Responden }\end{array}$ & $\begin{array}{c}\text { Persentase } \\
(\%)\end{array}$ & $\begin{array}{c}\text { Total } \\
\text { Skor }\end{array}$ \\
\hline Sangat Puas & 5 & 11 & $18,3 \%$ & 55 \\
Puas & 4 & 41 & $68,3 \%$ & 164 \\
Cukup Puas & 3 & 8 & $13,3 \%$ & 24 \\
Kurang Puas & 2 & - & - & - \\
Tidak Puas & 1 & - & - & - \\
\hline \multicolumn{2}{l}{ Jumlah } & 60 & $100 \%$ & 2 \\
\hline
\end{tabular}

Sumber: Diolah Dari Data Primer, 2019.

Berdasarkan pada Tabel 8, dapat diketahui bahwa responden yang menganggap puas mengenai fasilitas pendukung cukup menunjang (tv, musik, wifi) sebanyak 41 orang $(68,3 \%)$ dan menganggap sangat puas sebanyak 11 orang $(18,3)$ serta 2 orang $(13,3)$ cukup puas. Total skor yag diperoleh adalah 243 dan interpretasi sebesar $81 \%$. Dan termasuk kategori sangat puas.

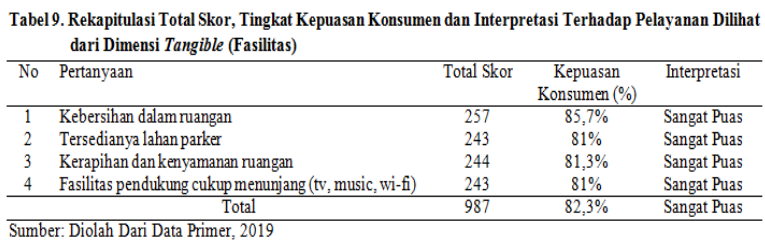

Tabel 9 menunjukan bahwa dari seluruh indikator tingkat kepuasan konsumen terhadap pelayanan terletak pada angka 744 dan persentase tingkat kepuasan konsumen sebanyak 82,3\%. Artinya konsumen sangat puas terhadap pelayanan Warunk Bendito dilihat dari dimensi Tangible dan indikator yang memperoleh persentase yang tinggi adalah kebersihan dalam ruangan yaitu sebanyak $85,7 \%$. Hal ini menunjukan bahwa responden sangat puas mengenai kebersihan dalam ruangan.

\section{Assurance (Kepastian)}

Assurance yaitu, meliputi kemampuan karyawan atas pengetahuan terhadap produk secara tepat, kualitas keramatamahan, perhatian dan kesopanan dalam memberikan pelayanan, ketrampilan dalam memberikan informasi.

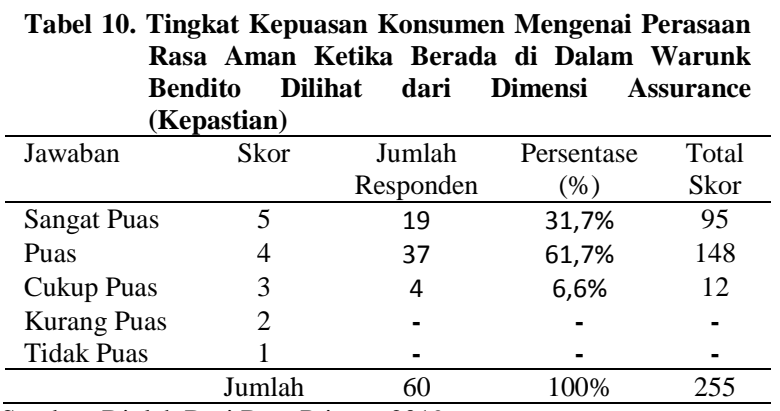

Sumber: Diolah Dari Data Primer, 2019
Berdasarkan pada Tabel 10, dapat diketahui bahwa jumlah responden yang paling banyak menjawab mengenai perasaan rasa aman ketika berada di dalam Warunk Bendito adalah puas yaitu sebanyak 37 orang $(61,7)$ dan yang menjawab sangat puas sebanyak 19 orang $(31,7 \%)$ serta yang menjawab cukup puas sebanyak 4 orang $(6,6 \%)$. Dengan total skor yang diperoleh 255 dan interpretasi sebanyak 85\%. Dan termasuk kategori sangat puas.

Tabel 11. Tingkat Kepuasan Konsumen Mengenai Perhatian dan Kesopanan Dalam Memberikan Pelayanan Dilihat dari Dimensi Assurance (Kepastian)

\begin{tabular}{|c|c|c|c|c|}
\hline Jawaban & Skor & $\begin{array}{c}\text { Jumlah } \\
\text { Responden }\end{array}$ & $\begin{array}{c}\text { Persentase } \\
(\%)\end{array}$ & $\begin{array}{l}\text { Total } \\
\text { Skor }\end{array}$ \\
\hline Sangat Puas & 5 & 18 & $30 \%$ & 90 \\
\hline Puas & 4 & 29 & $48,3 \%$ & 116 \\
\hline Cukup Puas & 3 & 13 & $21,7 \%$ & 39 \\
\hline Kurang Puas & 2 & - & - & - \\
\hline Tidak Puas & 1 & - & - & - \\
\hline & Jumlah & 60 & $100 \%$ & 245 \\
\hline
\end{tabular}

Sumber: Diolah Dari Data Primer, 2019.

Berdasarkan pada Tabel 11, dapat diketahui bahwa jumlah responden yag paling banyak menjawab mengenai perhatian dan kesopanan dalam memberikan pelayanan adalah puas yaitu sebanyak 29 orang $(48,3 \%)$ dan yang menjawab sangat puas sebanyak 18 orang (30\%) serta yang menjawab cukup puas sebanyak 13 orag $(21,7)$. Dan total skor yang diperoleh 245 dan interpretasi sebanyak 81,7\%. Dan termasuk kategori sangat puas.

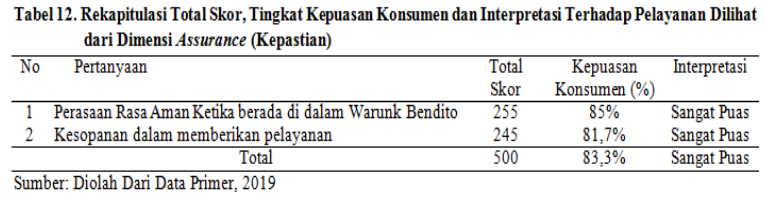

Tabel 12 menunjukan bahwa dari seluruh indikator tingkat kepuasan konsumen terhadap pelyanan terletak pada angka 500 dan persentase tingkat kepuasan konsumen sebanyak $83,3 \%$. Artinya konsumen sangat puas terhadap pelayan yang diberikan Warunk Bendito dilihat dari dimensi Assurance dan indikator yang memperoleh angka yang tinggi adalah perasaan rasa aman ketika berada di dalam Warunk Bendito yaitu sebanyak $85 \%$. Hal ini menunjukan bahwa konsumen sangat puas mengenai perasaan rasa aman ketika berada di dalam Warunk Bendito. 


\section{Emphaty (Simpati)}

Emphaty, yaitu perhatian secara individual yang diberikan perusahaan kepada pelanggan, seperti kemudahan untuk menghubungi perusahaan, kemampuan karyawan untuk berkomunikasi dengan pelanggan, dan usaha perusahaan untuk memahami kebutuhan dan keinginan pelanggannya.

Tabel 13. Tingkat Kepuasan Konsumen Mengenai Perhatian Kepada Setiap Kebutuhan Konsumen Dilihat dari Dimensi Emphaty (Simpati)

\begin{tabular}{lcccc}
\hline Jabawan & Skor & $\begin{array}{c}\text { Jumlah } \\
\text { Responden }\end{array}$ & $\begin{array}{c}\text { Persentase } \\
(\%)\end{array}$ & $\begin{array}{c}\text { Total } \\
\text { Skor }\end{array}$ \\
\hline Sangat Puas & 5 & 24 & $40 \%$ & 120 \\
Puas & 4 & 27 & $45 \%$ & 108 \\
Cukup Puas & 3 & 9 & $15 \%$ & 27 \\
Kurang Puas & 2 & - & - & - \\
Tida Puas & 1 & - & - & - \\
\hline \multicolumn{5}{r}{} \\
\hline
\end{tabular}

Sumber: Diolah dari data primer 2019

Berdasarkan pada Tabel 13, dapat diketahui bahwa jumlah responden yang paling banyak menjawab mengenai perhatian kepada setiap kebutuhan konsumen adalah puas yaitu sebanyak 27 orang (45\%) dan yang menjawb sangat puas sebanyak 24 orang (40\%) serta yang menjawab cukup puas sebanyak 9 orang $(15 \%)$. Dengan total skor yang diperoleh 255 dan interpretasi sebanyak $85 \%$. Artinya responden sangat puas mengenai perhatian kepada setiap kebutuhan pelanggan.

\section{Rekapitulasi Tingkat Kepuasan Konsumen Terhadap Pelayanan Warunk Bendito di Kawasan Megamas Manado Diliahat dari Dimensi Reliability, Responsive, Tangible, Assurance dan Emphaty}

Jumlah skor ideal untuk keseluruhan pertanyaan $=3000$ (Sangat Puas), jumlah skor terendah $=600$ (Tidak Puas). Berdasarkan data yang dihimpun dari 10 pertanyaan yang diajukan kepada 60 responden, maka diperoleh total skor 2496 dengan indeks tanggapan konsumen sebagai berikut:

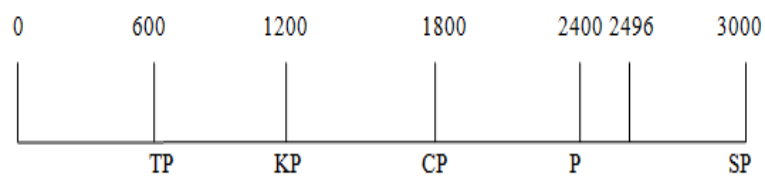

Gambar 4. Indeks Tingkat Kepuasan Konsumen Berdasarkan Data
Secara persentase, indeks Tingkat Kepuasan konsumen terletak pada:

$$
\begin{aligned}
\text { Kepuasan Konsumen } & =\frac{2496}{3000} \times 100 \% \\
& =83,2 \%
\end{aligned}
$$

Dengan indeks Tingkat Kepuasan konsumen yaitu:

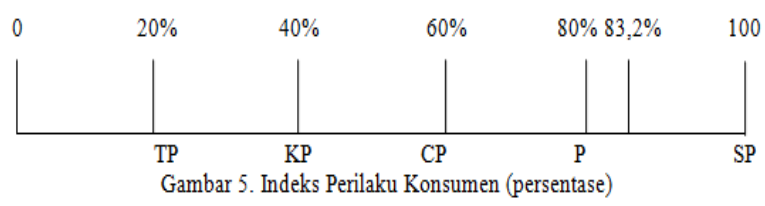

Berdasarkan hasil analisis mengunakan skala likert, maka dapat diketahui bahwa indeks tingkat kepuasan konsumen terhadap pelayanan Warunk Bendito di kawasan megamas Manado berada pada titik $83,2 \%$ termasuk dalam kategori sangat puas. Sebanyak 10 indikator pertanyaan tentang tingkat kepuasan konsumen terhadap pelayanan Warunk Bendito dilihat dari dimensi Reliability, Responsive, Tangible, Assurance dan Emphaty. Dari 5 dimensi tersebut Responsive yang memiliki persentase kepuasan konsumen yang paling tinggi yaitu sebesar $85,7 \%$. Hal ini menunjukkan bahwa konsumen merasa sangat puas terhadap indikator Responsive mengenai sikap ramah karyawan terhadap konsumen.

\section{KESIMPULAN DAN SARAN}

\section{Kesimpulan}

Tingkat kepuasan konsumen terhadap pelayanan Warunk Bendito di Kawasan Megamas Manado dilihat dari dimensi Reliability, Responsive, Tangible, Assurance, Emphaty terhadap tingkat kepuasan konsumen dalam pelayanan berada pada kategori sangat puas dalam pelayanan

\section{Saran}

1. Saran yang dapat diberikan berdasarkan hasil penelitian ini yaitu Warunk Bendito harus dapat mempertahankan tingkat kepuasan konsumen pada kategori sangat puas.

2. Perlu adanya penelitian lanjutan dengan penambahan indikator untuk aspek Reliability dan aspek Emphaty 


\section{DAFTAR PUSTAKA}

Tjiptono, F. 2002. Manajemen Jasa, Penerbit Andi Yogyakarta Majalah Info Bisnis, Edisi maret-Tahun ke VI.

Kotler, P. 2000, Manajemen Pemasaran, Edisi Milenium, Jakarta, Prehallindo.
Nugroho, dan Puriarta. 2011. "Analisis Kualitas Pelayanan Terhadap kepuasan Pasien Kamar Rawat Inap Kelas 2 pada Rumah Sakit Islam Jakarta”. AKTIVA, Volume 4 Nomor 7. 